\title{
Do Outside Options Reinforce or Weaken the Monopoly Power? -An Experiment Review
}

\author{
Gui-Rong SHAO \\ ${ }^{1}$ School of Economics, Zhejiang University, Zhejiang Province, P. R. China \\ aguirongshao@126.com
}

Keywords: Outside Option, Monopoly Power, Experiment.

\begin{abstract}
Consumers having outside options are an important continuation for market trading theory. The article discusses the question: allowing consumers to "shop around", does monopoly power sensitively respond to consumers with or without outside options? The related literatures were summarized and showed that there are three distinct opinions: outside options make the monopoly power more prone to compete; the monopoly power more prone to perfect monopoly level and outside options are not immediately relevant to the final trading. As the time over, monopoly power is significantly reduced; it converges to an intermediate value between monopoly and compete; but the convergence rate is not so fast.
\end{abstract}

\section{Introduction}

Compared with traditional shopping, the biggest breakthrough and innovation of online shopping, which makes new festivals "double eleven" and "double twelve" increasingly popular, is to eliminate the limitations of product categories and regions in entity stores. Therefore, there are enormous sources of optional products and consumers can fully "shopping around".

The classic trading theory implies hypothesis: consumers can only buy one kind of product in the "shop". This is far away from the real market transactions, especially away from the online transactions. There is a need to extend the research that consumers have only one homogeneous product trading to consumers have many other products to choose, i.e. consumers have outside options.

\section{Search, Outside Option and Monopoly Power}

Many real-world negotiations have repeatedly occurred in the shadow of outside options (Lee and Liu, 2013), as Rubinstein \& Wolinsky (1985) tried to peek into the black box, in the past thirty years, foreign researchers have explored the black box of market trading with outside options.

\section{Search and Monopoly Power}

Search capacity has an impact on searching alternative options for both sides in the game (Baucells and Lippman, 2004). The two major findings in literatures involving search should be noted.

One finding is that search is of high efficiency, in terms of gains (Sonnemans, 1998). Initially, researchers tested the basic model for work search through experimental method (Schotter and Braunstein, 1981), in a benchmarking study for comparison, the average retention salary given by participants was very close to the optimal level. After that, Cox \& Oaxaca (1990) and Schotter \& Braunstein conducted similar experiments as well, studied the search behaviors within a finite 20 periods. The risks faced by participants were neutral, when they expressed the retention salary, they made a promise that they would accept or refuse a job according to this salary automatically. The results showed that search duration has the same influence on the change direction for all parameters, except that at the beginning it was low and at the end it was high, the retention salary expressed by participants matched quite well with the optimal path. Almost at the same time, studies on search behaviors when shopping were also under way. Hey completed the experiment with participants having no payment under the unknown circumstance of price distribution. To continue Hey' study, Moon provided participants with more optional heuristic rules. Their experimental data indicates that in terms of participants' decision-making behavior, the use of 
truncation law can be explained as well as the standard optimal theory. Their computer simulation experiment also shows that the results by using heuristic decision-making rules are very close to the optimal results. Recently, Feri \& Gantner (2011) studied the implementation of other purchasing choices by trading side through search or return to negotiation. Over 80 percent of consumers behaved in exactly the same way as optimal stopping rule. In general, the search results are efficient, and traders' behaviors were very close to the optimal search strategy.

The other finding is that search behaviors are very few, compared with the optimal equilibriums (Schotter and Braunstein, 1981; Cox and Oaxaca, 1990, 2000). In Hey's (1987) another experiment with participants having payment, half of the participants knew the state of price distribution, this time, the frequency of applying the optimal retention price strategy by participants was significantly improved, but currency incentives cannot achieve this. In fact, the experiment showed that it's not necessarily a good thing for participants to recall the offers that refused earlier, the capacity may play an opposite role, leading to the decrease in total profits; which is confusing; and it may be the result of risk repugnance, participants only searched several times. Kogut carried out experimental study on search behaviors over an indefinite period. During each period, the participant had to pay a certain amount of cost, therefore chose from all kinds of possible prices from the known uniform distribution. The results of experiment suggested that participants often stopped searching prematurely, even if the level of risk repugnance was high, and most of the behaviors that stopped searching prematurely happened when the profits were offset by costs and turned to negative value, this indicated that many participants were sensitive to sunk costs, and not sensitive to $\mathrm{MC}$ and searching gains.

\section{Outside Option and Monopoly Power}

The simplest exploration to consumers with outside options is to study its special return to bargaining. Both searching trading parties have symmetric incomplete information, compared with the bargaining of complete information (Muthoo, 1995), the option to increase returnable negotiation is not trivial (Gantner, 2008; Board and Pycia, 2014). Gantner (2008) theoretically studied the incomplete information and non-cooperative bargaining between individual firm and consumer, introducing outside options for consumers, so consumers can choose returnable negotiation at any time, and regarding it as search process to build model. It should take two situations into consideration: when both trading parties have symmetric information about search and it is even when compared with complete information, then the conclusion of not delaying purchase is still tenable, meanwhile the returnable negotiation will no longer be unnecessary. The second is when both sides have asymmetric information about outside options, it is possible to delay purchase. Subsequently, based on Gantner's pure theory, Feri \& Gantner (2011) conducted the follow-up experimental study, tested the two bargaining games with bilateral incomplete information between individual firm and consumer. The results indicated that in the first game, there were no outside options, many participants didn't use incomplete information to gain profits as expected; the second game provided consumers with purchasing options through search or returnable negotiation, when the search result could be predicted, many consumers chose a bargaining agreement, for the outside options that have been made, the search results were generally efficient and the behaviors were quite close to the optimal search strategy. Zwick \& Lee (1999) carried out special experiment to study bargaining and search in detail, which tested the trading prices under two situations: returnable negotiation and non-returnable negotiation. Search happens randomly, consumers could choose to leave the negotiation table and search for other options, only one round of bargaining is allowed during the trading. Based on intuition and models, by comparing returnable and non-returnable negotiation, consumers could have more options, therefore they would have more control, thus resulting in lower prices.

However, the results of Zwick \& Lee's experiment indicated that in general, prices under returnable model were higher than non-returnable one, firms were sensitive to consumers' ability to return and accept the prices. If it was possible to return, firms would find that costs were high, and wouldn't encourage search by offering low prices, therefore, firms would offer "high" prices rather 
than low prices to discourage search. After the initial rejection, if consumers searched nothing, when the outside bidding was high enough, then the "high" bidding might be accepted afterwards, although it may depend on the prices. This implied that under the non- returnable model, firms would gain zero reward when the price was rejected, even though firms sincerely hoped, there was no other way to change consumers' mind, thus the non-returnable constraint was of strategic value, changing firms' expectation on consumers' future response. In fact, such non-returnable outside constraint strengthened the status of consumers. Another interesting observation was that, despite the two situations of returnable and non-returnable negotiations, high search costs all significantly lowered the profits of consumers, but didn't increase the profits of firms accordingly. In theory, the higher profits of consumers should be related to low prices, but in reality, higher profits under returnable negotiation are a result of lower search rate and returning back to accept the offer after search failure. That is to say, the lower profits of consumers can be attributed to unnecessary high search rate instead of higher prices.

As far as the general situation of consumers having outside options, few experiments explored. These experiments didn't even have search process. There are three distinct conclusions about the relationship between outside options and trading prices: Kirchkamp et al (2009) compared the equilibrium and bidding behaviors between the sealed first-price and second-price auction trading system with outside options. They found that bidders did respond to the changes of outside options and common information. First-price auction generated more revenue than the second-price one, its extra revenue was significantly higher when there were outside options. During the first-price auction, prices were significantly higher in the presence of outside options than in the absence of outside options, and the introduction of outside options into the second-price auction only had a minor effect. Kagel et al. (1987) had already observed the phenomenon of excessively high bids in the second-price auction. This was basically the same as the result of special case with outside options under the situation of returnable negotiation, and also the same as the conclusion of Board \& Pycia's theoretical study (2014). Secondly, in the context of bargaining, Binmore et al. (1989) predicted through theoretical analysis that outside options were not associated with the final trading. Its experimental results showed that the prediction was correct, if incomplete information or reputation effect was important, then outside options were not immediately related to the final trading. Thirdly, the experimental results of tough bargaining indicated that outside options made the threat of ending negotiation believable, and would increase the profits for participants with outside options, when the valuation of outside options was high, but was still lower than the current valuation, then trading was more inclined to the competitive level. When there was incomplete information, experimental results were still inclined to a more competitive trading (Binmore et al., 1989), i.e. the trading price was lower when there were outside options. Kuon (1994) found it even earlier that in the experiment when there was incomplete information about the outside options of the opposite party, the weak participants with undervalued outside options disguised as the strong participants with overvaluation, participants with higher valuation of outside options and more experience would trade with competitive prices.

\section{Intertemporal Dynamic Trend of Monopoly Power}

If we don't only take one period into account during trading, the intertemporal dynamic trend of prices theoretically is: the initial price of products is high, once consumers buy it, firms would lower the price (Montez, 2013); if consumers are patient enough, then the monopoly price converges almost immediately to the MC (Coase, 1972); under the situation of constant marginal cost and discrete time, when the time period is shortened to zero, then equilibrium will be close to the competitive level (Bond and Samuelson, 1984). But when Board \& Pycia (2014) considered that consumers may have other outside options, the theoretical conclusion drawn from that was totally different from the above scholars' opinions. Board \& Pycia embedded an individual firm model in a search framework, endogenous outside options, firm chose a range of prices during different periods, and consumers bought products from him. During each period, buyers could implement outside options, give up searching or turn to other sellers. Its theoretical conclusion showed that 
there was a unique equilibrium, in each period, firm asked for the same price, which was equal to the monopoly price.

In terms of multi-period trading experiments, there were only studies on situation without outside options. When Reynolds (2000) studied the complete monopoly firms, the experimental conclusion of consumers having no other outside options was that multi-period firms were inclined to decrease their bid progressively as time went on. While Mak et al. (2012) carried out experiment studies on the situation when duopoly firms and consumers paid with constant depreciation in each period. The results suggested that equilibrium prices decreased in each period progressively. Although these experimental literatures believed that during multiple periods, prices would decrease in different periods, they also believed that the prices wouldn't be as low as the marginal cost.

\section{Conclusion}

To sum up, on the one hand, there were three different conclusions when compared consumers having outside options with those having no outside options: outside options make the trading more prone to the competitive level; outside options make the trading more prone to monopolistic level and outside options are not immediately relevant to the final trading. On the other hand, in the intertemporal dynamic, manufacturers' monopoly power is significantly dropped; it converges to an intermediate value between monopoly and competitive level; but the convergence rate is not so fast.

These almost didn't take the search process into account. As mentioned earlier, search has two features: one is that search behaviors are very few, compared with the optimal equilibriums; the other is that search is of high efficiency. Therefore, it is necessary and reasonable to introduce sequential search into market experiment in the further research about manufacturers' monopoly power.

\section{References}

[1] Baucells, M., and Lippman, S. A. 2004, "Bargaining with search as an outside option: The impact of the buyer's future availability", Decision Analysis, 1(4), 235-249.

[2] Binmore, K., Shaked, A., and Sutton, J. 1989, “An outside option experiment”, The Quarterly Journal of Economics, 753-770.

[3] Board, S., and Pycia, M. 2014, "Outside options and the failure of the Coase conjecture", The American Economic Review, 104(2), 656-671.

[4] Bond, E. W., and Samuelson, L. 1984, "Durable good monopolies with rational expectations and replacement sales", The Rand Journal of Economics, 336-345.

[5] Coase, R. H. 1972, “Durability and monopoly”, JL \& Econ., 15, 143.

[6] Cox, J. C., and R. L. Oaxaca. "Unemployment Insurance and Job Search," in Research in Labor Economics, edited by L. J. Bassi, D. L. Crawford. Greenwich: JAI Press, 1990, 223-240.

[7] Feri, F., and A. Gantner. "Bargaining or Searching for a Better Price? - An Experimental Study." Games and Economic Behavior, 72(2), 2011, 376-99.

[8] Gantner, A. 2008, "Bargaining, search, and outside options", Games and Economic Behavior, 62(2), 417-435.

[9] Kagel, John H., Ronald M. Harstad, and Dan Levin, "Information impact and allocation rules in auctions with affiliated private values: A laboratory study", Econometrica: Journal of the Econometric Society 1987: 1275-1304.

[10] Kirchkamp, O., Poen, E., and Reiss, J. P. 2009, “Outside options: Another reason to choose the first-price auction”, European Economic Review, 53(2), 153-169. 
[11] Kuon, B. "Two-Person Bargaining with Incomplete Information.” In Two-Person Bargaining Experiments with Incomplete Information, edited by B. Kuon. Berlin Heidelberg: Springer, 1994, $5-10$.

[12] Lee, J., and Liu, Q. 2013, "Gambling reputation: Repeated bargaining with outside options", Econometrica, 81(4), 1601-1672.

[13] Montez, J. "Inefficient Sales Delays by a Durable-Good Monopoly Facing a Finite Number of Buyers." The RAND Journal of Economics, 44(3), 2013, 425-37.

[14] Muthoo, A. "On the Strategic Role of Outside Options in Bilateral Bargaining." Operations Research, 43(2), 1995, 292-7.

[15] Reynolds, S. S. 2000, "Durable-goods monopoly: laboratory market and bargaining experiments", The RAND Journal of Economics, 375-394.

[16] Rubinstein, A., and Wolinsky, A. 1985, "Equilibrium in a market with sequential bargaining", Econometrica: Journal of the Econometric Society, 1133-1150.

[17] Schotter, A., and Y. M. Braunstein. "Economic Search: An Experimental Study." Economic Inquiry, 19(1), 1981, 1-25.

[18] Sonnemans, J. "Strategies of Search." Journal of Economic Behavior \& Organization, 35(3), 1998, 309-32.

[19] Zwick, R., and C. C. Lee. "Bargaining and Search: An Experimental Study." Group Decision and Negotiation, 8(6), 1999, 463-87. 